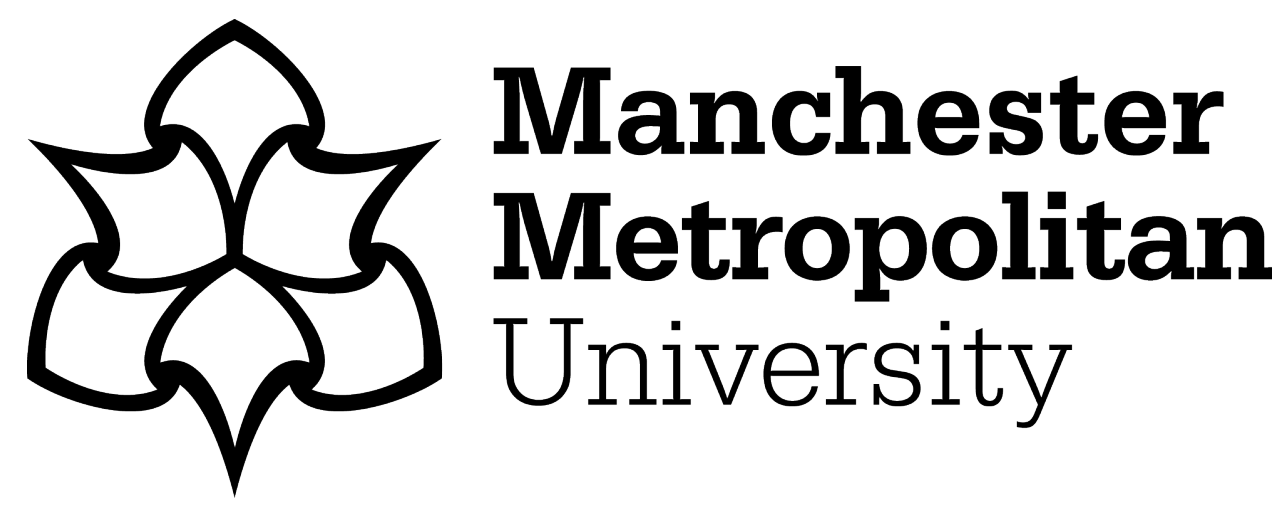

Alismaeel, ZT, Abbas, AS, Albayati, TM and Doyle, Aidan (2018) Biodiesel from batch and continuous oleic acid esterification using zeolite catalysts. Fuel, 234. pp. 170-176. ISSN 0016-2361

Downloaded from: https://e-space.mmu.ac.uk/621244/

Version: Accepted Version

Publisher: Elsevier

DOI: https://doi.org/10.1016/j.fuel.2018.07.025

Please cite the published version 


\title{
Biodiesel from batch and continuous oleic acid esterification using zeolite catalysts
}

\section{Ziad T. Alismaeel ${ }^{1}$ Ammar S. Abbas ${ }^{2}$ Talib M. Albayati ${ }^{3}$ Aidan M. Doyle ${ }^{4 *}$}

1. Department of Biochemical Engineering, Al-Khwarizmi College of Engineering, University of Baghdad, Al-Jadryah, P.O. Box 47008, Baghdad, Iraq. email: ziadalismaeel@yahoo.com.

2. Department of Chemical Engineering, College of Engineering, University of Baghdad, AlJadryah, P.O. Box 47221, Baghdad, Iraq. email: dr_ammar19@yahoo.com.

3. Department of Chemical Engineering, University of Technology, 52 Alsinaa St., PO Box 35010, Baghdad, Iraq. email: talib_albyati@yahoo.com.

4. Division of Chemistry and Environmental Science, Manchester Metropolitan University, Chester St., Manchester, M1 5GD, United Kingdom. email: a.m.doyle@mmu.ac.uk

* Corresponding author: a.m.doyle@mmu.ac.uk

\begin{abstract}
The esterification of oleic acid with ethanol was studied in both batch and continuous conditions in a fixed-bed reactor over FAU-type zeolites prepared from shale rock. The addition of Co-Ni-Pt to the zeolite increased the catalyst activity over the entire reaction temperature range. Experiments confirmed that esterification follows pseudo first-order kinetics. Thermodynamic analysis and Thiele modulus calculations show that the reaction is kinetically controlled in batch conditions, while diffusional limitations occur at higher flow rates when conducted in continuous mode. The maximum oleic acid conversions were recorded as $93 \%$ for batch and $89 \%$ for continuous, which exceed those of any analogous studies.
\end{abstract}


Keywords; Biodiesel, oleic acid esterification, zeolite, continuous fixed-bed reactor

\section{Introduction}

Biodiesel is a carbon neutral fuel source that has the potential to provide almost unlimited renewable energy. Untreated biodiesel (natural oils) e.g. sunflower oil, typically consists of fatty acids that require (trans)esterification to produce methyl or ethyl esters that have appropriate viscosity and burning rate (cetane number) for use in existing diesel compression engines thereby making them suitable as fuels. Biodiesel is traditionally prepared using homogeneous catalysts e.g. sulfuric acid. Heterogeneous catalysts have the advantage of being easily removed from the biodiesel produced so it is not surprising that more recent research efforts have focussed on the development and testing of such heterogeneous systems.

Oleic acid is present in natural oils and its acid catalysed esterification has become a model reaction in the study of biodiesel formation. Most of the literature around oleic acid esterification reports its reaction with methanol. Homogenous systems using mineral acid/base catalysts have been well studied so recent innovations in this area tend to focus on increasing the product yield by additional reaction treatment. Examples include the use of a water adsorption apparatus, which increases the reaction yield via water removal to enhance the oleic acid:methanol equilibrium towards the ester [1], and the application of ultrasound during reaction [2]. Heterogeneously catalysed oleic acid:methanol reactions have been reported over the following catalysts; Amberlyst-46 [3]; sulfonated carbon [4]; acid ion-exchange polymer resin [5]; titanium dioxide supported on natural phosphate [6]; 12-tungstophosphoric acid supported on mesoporous silica [7]; and solid acid catalysts prepared from Amazon flint kaolin [8]. Ethyl esters have superior properties to their methyl counterparts, evidenced by higher oil solubility, calorific value, cetane number, cold filtering plugging point, cloud point and pour 
point. The catalysis of the oleic acid:ethanol reaction has been examined using; sulfonated cation exchange resin [9]; organophosphonic acid-functionalised silica [10]; sulfonated carbonised bamboo ash [11]; Amberlyst-15 [12] niobic acid [13]; calcium ferrite [14]; and zirconia supported 12-tungstophosphoric acid [15].

Zeolites are high surface area solid acids that have been widely used for water treatment and purification, humidity control, and heterogeneous catalysis [16]. Zeolite acidity originates from the charge imbalance between silica and alumina units bound within the stable crystalline aluminosilicate framework; these properties makes zeolites suitable to the acid-catalysed esterification of free fatty acids in biodiesel production, and a number of reviews have been published [17-22]. In addition to their preparation from laboratory based silicate/aluminosilicates reagents, zeolites may also be prepared from a variety of natural/waste materials; the compositions of silicon and aluminium based minerals in these materials is similar to those of aluminosilicate zeolites, and the literature describes examples of zeolites prepared from fly ash [23-33], kaolin [34-45], fly ash-kaolinite [46] and shale [47-51]. There are few reports in the literature on zeolite catalysed oleic acid esterification reactions, and the majority use methanol; zeolite beta [52,53]; mordenite, ZSM-5 and FAU-type zeolite [54]; and ZSM-5 modified with citric acid [55]. Oleic acid esterification with ethanol was studied in batch conditions over zeolite Y [56] and zeolite beta [57], and via pervaporation-assisted continuous esterification over Amberlyst-15 [58] and NaA zeolite membrane [59].

We recently reported the preparation of pure FAU- zeolite from shale rock, and demonstrated that its catalytic activity was comparable to that of commercial Y zeolite in the esterification of oleic acid with ethanol [51]. Here, we expand on our previous experiments using FAU-type zeolite as a catalyst in both batch and continuous conditions, in which the maximum conversion 
is enhanced by the straightforward addition of Co-Ni-Pt metals. Kinetic and thermodynamic parameters are also presented.

\section{Experimental}

\subsection{Materials}

The following is a list of the materials' source/supplier and purity; shale rock was collected from the surface of a tilled field on a working farm in county Wexford, Ireland, washed with water to remove all soil residue and dried at $120^{\circ} \mathrm{C}$ for three hours; sodium hydroxide $(\mathrm{NaOH})$ pellets, extra pure, Scharlau; sodium silicate $\left(\mathrm{Na}_{4} \mathrm{SiO}_{4}\right), 99 \%$ purity, BDH Chemicals Ltd.; ammonium chloride $\left(\mathrm{NH}_{4} \mathrm{Cl}\right)$, Sigma Aldrich; absolute ethanol $\left(\mathrm{C}_{2} \mathrm{H}_{5} \mathrm{OH}\right)$ Sigma Aldrich; phenolphthalein, $2 \%$ in ethanol, Sigma-Aldrich; cobalt (II) nitrate hexahydrate, $\mathrm{Co}\left(\mathrm{NO}_{3}\right)_{2} \cdot 6 \mathrm{H}_{2} \mathrm{O}$, Sigma Aldrich; nickel (II) nitrate hexahydrate, $\mathrm{Ni}\left(\mathrm{NO}_{3}\right)_{2} \cdot 6 \mathrm{H}_{2} \mathrm{O}$, Sigma Aldrich; platinum (IV) oxide hydrate, $\mathrm{PtO}_{2} \cdot \mathrm{xH}_{2} \mathrm{O}$, Sigma Aldrich.

\subsection{Catalyst preparation}

The zeolite was prepared using a procedure based on our previous paper [51]. The washed shale was crushed in a ball mill apparatus, sieved to $<90 \mu \mathrm{m}$ and calcined in air at $800{ }^{\circ} \mathrm{C}$ for $4 \mathrm{~h}$ to remove organic matter. $10 \mathrm{~g}$ of calcined shale was then refluxed with $40 \mathrm{~cm}^{3}$ of $5 \mathrm{M} \mathrm{HCl}$ at $85{ }^{\circ} \mathrm{C}$ for $4 \mathrm{~h}$ (to remove $\mathrm{Fe}$ ) and the product recovered by filtration. 1 part (by mass) of calcined shale was mixed with 1.5 parts (by mass) of $40 \mathrm{wt} \%$ aqueous $\mathrm{NaOH}$ solution, heated at $850{ }^{\circ} \mathrm{C}$ in air for $3 \mathrm{~h}$ in a furnace to get fused shale, which was crushed to powder form after cooling to ambient temperature. $2 \mathrm{~g}$ of fused shale, $1 \mathrm{~g}$ sodium silicate and $16 \mathrm{~g}$ distilled water were added to a polypropylene bottle, stirred at room temperature for $3 \mathrm{~h}$, then aged under static conditions at room temperature for $18 \mathrm{~h}$, and finally hydrothermally treated at $100{ }^{\circ} \mathrm{C}$ for $24 \mathrm{~h}$. The product was recovered by filtration. 
To convert the prepared zeolite from $\mathrm{Na}^{+}$to $\mathrm{NH}_{4}{ }^{+}$form, $90 \mathrm{~g}$ of zeolite were added to $250 \mathrm{~cm}^{3}$ of $2 \mathrm{M}$ ammonium chloride and stirred in a round bottom flask at room temperature for $2 \mathrm{~h}$. The solid was recovered by filtration, washed with distilled water and the ion-exchange procedure was repeated a further two times using $60 \mathrm{~g}$ and $30 \mathrm{~g}$, respectively. The solid was again recovered by filtration, washed with distilled water, dried for $12 \mathrm{~h}$ at $120^{\circ} \mathrm{C}$ and calcined in air at $500{ }^{\circ} \mathrm{C}$ for $4 \mathrm{~h}$ to give zeolite in $\mathrm{H}^{+}$form, hereafter labelled H-FAU.

Before metal loading, the zeolite was dried in an oven at $110{ }^{\circ} \mathrm{C}$ for $2 \mathrm{~h}$ to remove any absorbed water. Precious metals were added to the zeolite using incipient wetness; solutions were prepared by dissolving the appropriate masses of $\mathrm{Co}, \mathrm{Ni}$, and Pt metal precursors in $0.1 \mathrm{M} \mathrm{HCl}$, which were then added to the zeolite to give loadings of $1 \mathrm{wt} . \%$ of each metal. After impregnation, the catalysts were dried overnight at ambient temperature, heated for $24 \mathrm{~h}$ at 120 ${ }^{\circ} \mathrm{C}$, and calcined in air at $500{ }^{\circ} \mathrm{C}$ for $4 \mathrm{~h}$ to give Co-Ni-Pt-FAU.

\subsection{Characterization}

Nitrogen adsorption/desorption measurements were carried out using a Micromeritics ASAP 2020 Surface Analyser at $-196^{\circ} \mathrm{C}$. Samples were degassed under vacuum $\left(\mathrm{p}<10^{-5} \mathrm{mbar}\right)$ for $12 \mathrm{~h}$ at $350{ }^{\circ} \mathrm{C}$ prior to analysis. BET surface areas of the samples were calculated in the relative pressure range 0.05-0.30. Microscopic images were recorded using a JEOL JSM-5600LV scanning electron microscope (SEM). Semi-quantitative chemical analysis was performed by energy-dispersive X-ray spectroscopy (EDAX) using a detector from Oxford Instruments.

\subsection{Catalyst testing}

\subsubsection{Batch reactor}


The esterification reaction of oleic acid with ethanol was performed by reflux in a $500 \mathrm{ml}$ batch reactor placed in a thermostatic oil bath under stirring. The desired amount of catalyst was dried before reaction at $130{ }^{\circ} \mathrm{C}$ for $2 \mathrm{~h}$. The reactor was loaded with $50 \mathrm{ml}(44.75 \mathrm{~g})$ of oleic acid and the desired amount of pre-heated ethanol was then added to give an ethanol to oleic acid molar ratio of 6. Esterification was carried out at reaction temperatures 40, 50, 60 and 70 ${ }^{\circ} \mathrm{C} .5 \mathrm{ml}$ samples were withdrawn from the reaction mixture at 15 minute intervals, and centrifuged for $10 \mathrm{~min}$ at $3000 \mathrm{rpm}$ to separate the solid zeolite from the liquid phase.

The supernatant layer was purified by rotary evaporator to remove excess ethanol and water generated during reaction and analysed by titration with $0.1 \mathrm{M} \mathrm{KOH}$, using phenolphthalein indicator, to calculate the acid value (AV) as shown in the following equation;

$$
\mathrm{AV}=\frac{\mathrm{ml} \text { of } \mathrm{KOH} \times \mathrm{N} \times 56}{\text { Weight of Sample }}
$$

From the acid value, the conversion of oleic acid was calculated for each amount of catalyst as shown in the following equation;

$$
\text { conversion } \%=\frac{\mathrm{AV}_{\mathrm{t} 0}-\mathrm{AV} \mathrm{t}}{\mathrm{AV}_{\mathrm{t} 0}} \times 100 \%
$$

where:

$\mathrm{AV}_{\text {to }}$ (acid value of the reaction product at time 0 )

$\mathrm{AV}_{\mathrm{t}}$ (acid value of the reaction product at time $\mathrm{t}$ )

\subsubsection{Continuous fixed-bed reactor}

Oleic acid esterification was conducted in continuous mode using a vertical fixed-bed quartz reactor (Fig. 1) with internal diameter $10 \mathrm{~mm}$ and height $650 \mathrm{~mm} .6 .35 \mathrm{~g}$ of catalyst pellets 
were prepared by compressing the catalyst powder at 2 tonnes for $1 \mathrm{~min}$ in a hydraulic press, followed by crushing and sieving to the size range 355 to $500 \mu \mathrm{m}$. Ethanol and oleic acid were mixed and preheated (using the same quantities as in the batch reaction), and delivered upwards to the reactor using a Perkin Elmer LC pump. The reaction temperature was controlled by circulating water from a bath. Different flow rates were employed to obtain sufficient residence times between the reactants and catalyst inside the reactor column $(30,60,90,120,150$ and 180 mins). The product stream was collected in an accumulation tank, during which $10 \mathrm{ml}$ samples were taken for analysis at each flow rate and temperature. The product was purified and analysed in the same manner as that used in the batch reaction.

\section{Results and Discussion}

\subsection{Characterisation}

The XRD patterns for H-FAU prepared from shale rock confirm the faujasite structure; these were discussed in detail by the authors in reference 51 so will not be repeated here. The BET surface area of H-FAU decreased from $571 \mathrm{~m}^{2} \mathrm{~g}^{-1}$ to $490 \mathrm{~m}^{2} \mathrm{~g}^{-1}$ after the addition of Co, Ni and Pt metal salts by incipient wetness, and subsequent heating and calcination in air. A decrease in surface area is expected as the Co-Ni-Pt-FAU has undergone twice the period of calcination as H-FAU, thereby causing some loss of the metastable zeolite porosity but, nonetheless, retains a high surface area. SEM images, Fig. 2, show the characteristic micron sized particles, approximately $2 \mu \mathrm{m}$, of both H-FAU and Co-Ni-Pt-FAU, while EDAX confirms the presence of cobalt, nickel and platinum in addition to silicon and aluminium in the underlying zeolite.

\subsection{Esterification reactions}

The esterification of oleic acid with ethanol is used as a test reaction to assess the catalytic activity of the shale zeolite. This is a reversible reaction so an excess quantity of ethanol, 6:1 
ethanol/oleic acid molar ratio, is used to enhance conversion. The fractional conversions of oleic acid over H-FAU, Fig 3, increase with reaction time at all temperatures where the maximum conversion increases from $45 \%$ at $40{ }^{\circ} \mathrm{C}$ to $78 \%$ at $70{ }^{\circ} \mathrm{C}$. The addition of Co-Ni-Pt increases the catalyst activity over the entire temperature range such that the maximum conversion increases from $58 \%$ at $40{ }^{\circ} \mathrm{C}$ to $93 \%$ at $70{ }^{\circ} \mathrm{C}$. The activity of the Co-Ni-Pt-FAU catalyst exceeds those of the zeolite Y prepared from kaolin in our previous study, and also that of a commercially sourced $\mathrm{Y}$ zeolite in $\mathrm{H}-$ form $\left(85 \%\right.$ at $\left.70{ }^{\circ} \mathrm{C}\right)$ [45].

As previously noted, most of the literature documenting zeolite catalysed oleic acid esterification uses methanol as the alcohol reagent; maximum conversion rates (of oleic acid) were reported as follows; $86 \%$ for zeolite beta [52,53]; $81 \%$ for mordenite, $80 \%$ for ZSM-5, and $78 \%$ for FAU-type zeolite [54]; $80 \%$ for ZSM-5 [55]; and 83\% for citric acid modified ZSM-5 [56]. For zeolite catalysed oleic acid and ethanol batch esterification. Marchetti et al. reported a maximum conversion of $27 \%$ after two hours over $\mathrm{Na}-\mathrm{Y}$ zeolite at $55{ }^{\circ} \mathrm{C}$ using an ethanol:oleic acid ratio of $6.3: 1$; the low value of $27 \%$ is likely to be due to using the $\mathrm{Na}^{+}$form of zeolite, which is much less acidic than the $\mathrm{H}^{+}$form [56]. Sun et al. reported a conversion rate of $73.6 \%$ over zeolite beta after 10 hours at $78{ }^{\circ} \mathrm{C}$ using an ethanol:oleic acid ratio of $20: 1$ [57]. The zeolite prepared here from shale is more active than either of these catalysts, evidenced by conversions of $59 \%$ at $50{ }^{\circ} \mathrm{C}$ and $71 \%$ at $60{ }^{\circ} \mathrm{C}$, versus $27 \%$ at $55{ }^{\circ} \mathrm{C}$ over $\mathrm{Na}-\mathrm{Y}$ [56], and $78 \%$ at $70{ }^{\circ} \mathrm{C}$ versus $73.6 \%$ at $78{ }^{\circ} \mathrm{C}$ over zeolte beta [57].

Reaction rate constants were calculated from plots of $\ln$ oleic acid concentration versus time, Fig. 4; the gradients are the pseudo first-order rate constants (ethanol in excess) which are then converted to the 'true' second-order rate constants by accounting for the concentration of ethanol. The best fits were found to occur up to and including 1 hour reaction time; thereafter 
the reaction approaches/reaches equilibrium where the extent of the reverse hydrolysis reaction is such that the measurement of oleic acid alone is insufficient for a meaningful kinetic study. All plots showed excellent linearity (regression coefficient 0.99 or greater). The pseudo firstorder and second-order rate constants, Table 2, increase with both reaction temperature and the addition of Co-Ni-Pt to the zeolite. The vast majority of papers in the literature do not report the second-order rate constants. This is unfortunate, as their inclusion would allow a direct comparison of catalyst activities between research groups doing similar studies. The pseudo first-order rate constant is sometimes mentioned but, on its own, is not an accurate means of disseminating catalyst activity for the purpose of comparison, due to the numerical value not accounting quantitatively for the excess alcohol concentration.

The Arrhenius parameters of oleic acid esterification were calculated from the second-order rate constants, Fig. 5, giving activation energies of $28.6 \mathrm{~kJ} \mathrm{~mol}^{-1}$ for $\mathrm{H}-\mathrm{FAU}$ and $31.9 \mathrm{~kJ} \mathrm{~mol}^{-1}$ for Co-Ni-Pt-FAU, Table 1. The slightly higher activation energy over the Co-Ni-Pt-FAU catalyst is surprising, given the associated higher rates of reaction relative to H-FAU. However, activation energy is a measure of the temperature response of an activated reaction and the results here may simply indicate a different reaction mechanism over Co-Ni-Pt-FAU (at least for a portion of reacting molecules). This is somewhat confirmed by the higher value of the Arrhenius frequency factor; $16804 \mathrm{dm}^{3} \mathrm{~mol}^{-1} \mathrm{~h}^{-1}$ for Co-Ni-Pt-FAU versus $3886 \mathrm{dm}^{3} \mathrm{~mol}^{-1} \mathrm{~h}^{-1}$ for H-FAU. It is not possible to make a direct comparison of these Arrhenius frequency factors to those from other studies as most papers make no such mention, and for those that do, the numerical value and units are calculated using the pseudo-first order rate constants. The Arrhenius frequency factor is an approximate measure of the collision rate of reacting molecules. Accordingly, we tentatively attribute the higher Arrhenius frequency factor to the greater affinity of oleic acid to the metal surface(s) (as opposed to the underlying zeolite), 
which concentrates the oleic acid solution near the zeolite acid sites thereby increasing the reaction rate. (It is important to note that the esterification reaction is catalysed by the zeolite acid sites, and not necessarily $\mathrm{Co}, \mathrm{Ni}$ or Pt.) This increased affinity may be due to the direct adsorption/interaction between the oleic acid double bond and the metal phase e.g. Pt. The resulting increase in oleic acid concentration near the zeolite surface could also increase any ionic interaction between the carboxylic acid group of oleic acid and the zeolite surface, providing further reactant concentration and an associated increase in reaction rate.

Activation energies $>20 \mathrm{~kJ} \mathrm{~mol}^{-1}$ are consistent with kinetically controlled reactions, so the results here confirm that the oleic acid esterification reaction over FAU-zeolite is kinetically controlled i.e. not diffusion limited [60]. The extent of diffusion may be evaluated more precisely using the Thiele modulus, $\phi$, which for a spherical particle of radius $R$ (such as that in the present paper of SEM diameter $2 \mu \mathrm{m}$ ) is calculated using the following equation [61]:

$$
\phi=\frac{R}{3} \sqrt{\frac{k^{\prime}}{D_{\text {eff }}}}
$$

This approach thus combines a theoretical calculation of the effective diffusion coefficient,

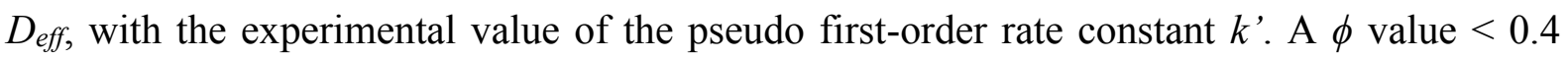
indicates that the reaction concentration profile does not drop significantly within the catalyst pores i.e. the reaction is not diffusion limited. The effective diffusion coefficient was calculated using the following equation [62]:

$$
D_{e f f}=\frac{D_{A B} \varepsilon_{p}}{\tau_{p}}
$$

where $\mathrm{D}_{\mathrm{AB}}$ is the molecular diffusion coefficient of the limiting reactant $\mathrm{A}$ in solvent $\mathrm{B}, \varepsilon_{p}$ is the catalyst particle porosity and $\tau_{p}$ is the catalyst pore tortuosity. For the study presented here, 
the molecular diffusion coefficient of oleic acid in ethanol was calculated using the WilkeChang method [63] to be $5.27 \times 10^{-11} \mathrm{~m}^{2} \mathrm{~s}^{-1}$ at $40{ }^{\circ} \mathrm{C}$, which is similar to that calculated for triglyceride in methanol, $6.1 \times 10^{-11} \mathrm{~m}^{2} \mathrm{~s}^{-1}$ [64]. The Thiele modulus values were calculated for each batch reaction using an $\varepsilon_{p}$ value of 0.345 , determined from the nitrogen adsorption void fraction, and a $\tau_{p}$ value of 4 [62]. The calculated values, Table 1, range from $5.68 \times 10^{-4}$ to 8.01 $\mathrm{x} 10^{-4}$, which is well below 0.4 thereby providing further evidence that the reaction is kinetically controlled i.e. not diffusion limited.

The increased reaction rate using Co-Ni-Pt-FAU is also evident when the reaction is conducted on a continuous basis in the fixed-bed reactor. The maximum conversions of oleic acid, Fig. 6 , reach $41 \%$ at $40{ }^{\circ} \mathrm{C}$ and $75 \%$ at $70{ }^{\circ} \mathrm{C}$ over $\mathrm{H}-\mathrm{FAU}$, while the equivalent figures over Co-NiPt-FAU are 54\% and $89 \%$, respectively. Pseudo first-order kinetics were confirmed for both H-FAU and Co-Ni-Pt-FAU catalysts when used in the fixed-bed reactor, Fig. 7, which matches with the rate law found in batch. It is interesting to note that the kinetic treatment showed the greatest linearity of fit at lower LHSVs, particularly so in the case of Co-Ni-Pt-FAU. Further evidence of the superior catalytic activity by the addition of Co-Ni-Pt can be seen in Fig. 7, where the absolute reaction rates (measured as the quantity of oleic acid converted) are plotted. Visual inspection of both H-FAU and Co-Ni-Pt-FAU gradients shows that, overall, the reaction rates for most catalysts increase relatively linearly up to one hour reaction time, and, thereafter, there is a noticeable reduction in the degree of increase. This change in response is due to diffusional limitations where the reactant flow rates are sufficiently high to prevent complete reaction (these effects are currently under investigation and will not be discussed here as they are beyond the scope of this paper). However, it is interesting to examine the dynamics of rate changes at times greater than one hour. In the case of H-FAU, the reaction rates decrease slightly between one and two hours at temperatures $40{ }^{\circ} \mathrm{C}$ and $50{ }^{\circ} \mathrm{C}$, but increase at $60{ }^{\circ} \mathrm{C}$ and 
$70{ }^{\circ} \mathrm{C}$. For Co-Ni-Pt-FAU, the rates increase at all temperatures over the same range. This effect is due to the higher reaction rate caused by the $\mathrm{Co}, \mathrm{Ni}$ and $\mathrm{Pt}$ on the zeolite; while the contribution by the metals is insufficient to eliminate the diffusion effects entirely, it does nonetheless partially mitigate the diffusional limitations, and increases the absolute reaction rate overall.

To our knowledge, there are no other reports of zeolite catalysed oleic acid esterification with ethanol under continuous conditions. Zeolites have however been used to remove water by pervaporation, where a non-zeolitic material was the active catalyst. Han et al. reported a maximum conversion of $84.2 \%$ over a cation exchange resin catalyst, that increased to $87.1 \%$ when a NaY zeolite membrane was added for pervaporation [59]. The maximum conversions of the same reaction under continuous conditions, but which do not incorporate zeolites, are up to $55 \%$ from $50-70{ }^{\circ} \mathrm{C}$ using Amberlyst-15, and up to $90 \%$ at $249{ }^{\circ} \mathrm{C}$ using niobic acid [13]. Considering the reactions in this paper used a maximum temperature $70{ }^{\circ} \mathrm{C}$ and reaction time 1.5-2 h, our conversion results, $93 \%$ batch and $89 \%$ continuous, obtained without the need for pervaporation, are particularly promising.

\section{Conclusions}

Shale rock is found to be an excellent natural material to prepare FAU-type zeolite for the catalysed esterification of oleic acid and ethanol, a model reaction for biodiesel production. The conversion rates increased in both batch and continuous conditions with temperature and the addition of $\mathrm{Co}, \mathrm{Ni}$ and $\mathrm{Pt}$ to the zeolite. Kinetic and thermodynamic studies proved that the reaction is pseudo first-order, with respect to oleic acid, and is kinetically controlled. On a wider level, these findings confirm the suitability of using zeolites as heterogeneous catalysts in biodiesel preparation. 


\section{Acknowledgments}

ZTA is grateful to the Iraqi Ministry of Higher Education and Scientific Research for financial support to carry out this work at Manchester Metropolitan University, UK, as a part of the requirements for the degree of Doctor of Philosophy in Chemical Engineering at the University of Baghdad.

\section{References}

1. Lucenaa IL, Saboya RMA, Oliveira JFG, Rodrigues ML, Torres AEB, Cavalcante Jr CL, Parente Jr EJS, Silva GF, Fernandes FAN. Oleic acid esterification with ethanol under continuous water removal conditions. Fuel 2011:90:902-904.

2. Lee SB, Lee JD, Hong IK. Ultrasonic energy effect on vegetable oil based biodiesel synthetic process. J. Ind. Eng. Chem. 2011:17:138-143.

3. Ilgen O. Investigation of reaction parameters, kinetics and mechanism of oleic acid esterification with methanol by using Amberlyst 46 as a catalyst. Fuel Proc. Tech. 2014:124:134-139.

4. Geng L, Wang Y, Zhu Y. Efficient carbon-based solid acid catalysts for the esterification of oleic acid. Catal. Comm. 2011:13:26-30.

5. Tesser R, di Serio M, Guida M, Nastasi M, Santacesaria E. Kinetics of oleic acid esterification with methanol in the presence of triglycerides. Ind. Eng. Chem. Res. 2005:44:7978-7982.

6. Essamlali Y, Larzek M, Essaid B, Zahouily M. Natural phosphate supported titania as a novel solid-acid catalyst for oleic acid esterification. Ind. Eng. Chem. Res. 2017:56:5821-5832. 7. Patel A, Brahmkhatri V. Kinetic study of oleic acid esterification over 12-tungstophosphoric acid catalyst anchored to different mesoporous silica supports. Fuel Proc. Tech. 2013:113:141149. 
8. do Nascimento LAS, Tito LMZ, Angelica RS, da Costa CEF, Zamian JR, Rocha Filho GN. Esterification of oleic acid over solid acid catalysts prepared from Amazon flint kaolin. Appl. Cat. B: Environ. 2011:101:495-503.

9. Jiang Y, Lu J, Sun K, Ma L, Ding J. Esterification of oleic acid with ethanol catalyzed by sulfonated cation exchange resin: Experimental and kinetic studies. Energy Conv. Management. 2013:76:980-985.

10. Yin P, Chen L, Wang Z, Qu R, Liu X, Ren S. Production of biodiesel by esterification of oleic acid with ethanol over organophosphonic acid-functionalised silica. Bioresource Technol. 2012:110:258-263.

11. Zhou Y, Niu S, Li J. Activity of the carbon-based heterogeneous acid catalyst derived from bamboo in esterification of oleic acid with ethanol. Energy Conv. Management. 2016:114:188196.

12. Hykkerud A, Marchetti JM. Esterification of oleic acid with ethanol in the presence of Amberlyst-15. Biomass Bioenergy 2016:95:340-343.

13. Rade LL, Lemos COT, Barrozo MAS, Ribas RM, Monteiro RS, Hori CE. Optimization of continuous esterification of oleic acid with ethanol over niobic acid. Renewable Energy 2018:115:208-216.

14. Ong HR, Khan MMR, Yousuf A, Hussain NA, Cheng CK. Synthesis and characterization of a $\mathrm{CaFe}_{2} \mathrm{O}_{4}$ catalyst for oleic acid esterification. RSC Adv. 2015:5:100362-100368.

15. Oliveira CF, Dezaneti LM, Garcia FAC, de Macedo JL, Dias JA, Dias SCL, Alvim KSP. Esterification of oleic acid with ethanol by 12-tungstophosphoric acid supported on zirconia. Appl. Catal. A:General 2010:372:153-161.

16. Weitkamp J. Zeolites and catalysis. Solid State Ionics 2000;131;175-188. 
17. Lee AF, Bennet JA, Manayil JC, Wilson K. Heterogeneous catalysis for sustainable biodiesel production via esterification and transesterification. Chem. Soc. Rev. 2014;43;78877916.

18. Su F, Guo Y. Advancements in solid acid catalysts for biodiesel production. Green Chem. $2014 ; 16 ; 2934-2957$.

19. Lam MK, Lee KT, Mohamed AR. Homogeneous, heterogeneous and enzymatic catalysis for transesterification of high free fatty acid oil (waste cooking oil) to biodiesel: A review. Biotech. Adv. 2010;28;500-518.

20. Semwal S, Arora AK, Badoni RP, Tuli DK. Biodiesel production using heterogeneous catalysts. Bioresource Technol. 2011;102;2151-2161.

21. Borges ME, Diaz L. Recent developments on heterogeneous catalysts for biodiesel production by oil esterification and transesterification reactions: A review. Renew. Sust. Energy Rev. 2012;16;2839-2849.

22. Melero JA, Iglesias J, Morales G. Heterogeneous acid catalysts for biodiesel production: current status and future challenges. Green Chem. 2009;11;1285-1308.

23. Querol X, Moreno N, Umaña JC, Alastuey A, Hernández E, López-Soler A, Plana F. Synthesis of zeolites from coal fly ash: an overview. Int. J. Coal Geol. 2002;50;413-423.

24. Querol X, Umaña JC, Plana F, Alastuey A, López-Soler A, Medinaceli A, Valero A, Domingo MJ, Garcia-Rojo E. Synthesis of Na zeolites from fly ash in a pilot plant scale. Examples of potential environmental applications. Fuel 2001;80;857-865.

25. Norihiro M, Yamamoto H, Shibata J. Mechanism of zeolite synthesis from coal fly ash by alkali hydrothermal reaction. Int. J. Miner. Process. 2002;64;1-17.

26. Tanaka H, Matsumura S, Hino R. Formation process of Na-X zeolites from coal fly ash. J. Mater. Sci. 2004;39;1677-1682. 
27. Wałek TT, Saito F, Zhang Q. The effect of low solid/liquid ratio on hydrothermal synthesis of zeolites from fly ash. Fuel 2008;87;3194-3199.

28. Tanaka H, Fujii A. Effect of stirring on the dissolution of coal fly ash and synthesis of pureform Na-A and -X zeolites by two-step process. Adv. Powder Technol. 2009;20;473-479.

29. Gross-Lorgouilloux M, Gaullet P, Soulard M, Patarin J, Moleiro E, Saude I. Conversion of coal fly ashes into faujasite under soft temperature and pressure conditions. Mechanisms of crystallisation. Microporous Mesoporous Mater. 2010;131;407-417.

30. Shigemoto N, Hayashi H, Miyaura K. Selective formation of Na-X zeolite from coal fly ash by fusion with sodium hydroxide prior to hydrothermal reaction. J. Mater. Sci. $1992 ; 28 ; 4781-4786$.

31. Chang H.-L, Shih W.-H. A general method for the conversion of fly ash into zeolites as ion exchangers for cesium. Ind. Eng. Chem. Res. 1998;37;71-78.

32. Molina A, Poole C. A comparative study using two methods to produce zeolites from fly ash. Miner. Eng. 2004;17;167-173.

33. Tosheva L, Brockbank A, Mihailova B, Sutula J, Ludwig J, Potgieter H, Verran J. Micronand nanosized FAU-type zeolites from fly ash for antibacterial applications. J. Mater. Chem. $2012 ; 22 ; 16897-16905$.

34. Belviso C, Cavalcante F, Lettino A, Fiore S. A and X-type zeolites synthesised from kaolinite at low temperature. Appl. Clay Sci. 2013;80-81;162-168.

35. Holmes SH, Alomair AA, Kovo AS. The direct synthesis of pure zeolite-A using 'virgin' kaolin. RSC Adv. 2012; 2;11491-11494.

36. Holmes SH, Khoo SH, Kovo AS. The direct conversion of impure natural kaolin into pure zeolite catalysts. Green Chem. 2011;13;1152-1154. 
37. Kovo AS, Hernandez O, Holmes SH. Synthesis and characterization of zeolite Y and ZSM5 from Nigerian Ahoko kaolin using a novel, lower temperature, metakaolinization technique. J. Mater. Chem. 2009;19;6207-6212.

38. Shen B, Wang P, Yi Z, Zhang W, Tong X, Liu Y, Guo Q, Gao J, Xu C. Synthesis of zeolite $\beta$ from kaolin and its catalytic performance for FCC naphtha aromatization. Energy \& Fuels $2009 ; 23 ; 60-64$.

39. Shen K, Qian W, Wang N, Zhang J, Wei F. Direct synthesis of c-axis oriented ZSM-5 nanoneedles from acid-treated kaolin clay. J. Mater. Chem. A 2013;1;3272-3275.

40. Caballero I, Colina FG, Costa J. Synthesis of X-type zeolite from dealuminated kaolin by reaction with sulfuric acid at high temperature. Ind. Eng. Chem. Res. 2007;46;1029-1038.

41. Wan G, Duan A, Zhang Y, Zhao Z, Jiang G, Zhang D, Gao Z, Liu J, Chung KH. Hydrodesulfurization of fluidized catalytic cracking diesel oil over NiW/AMB catalysts containing H-type $\beta$-zeolite in situ synthesized from kaolin material. Energy \& Fuels $2009 ; 23 ; 3846-3852$.

42. de Lucas A, Uguina MA, Covian I, Rodriguez L. Use of Spanish natural clays as additional silica sources to synthesize 13X zeolite from kaolin. Ind. Eng. Chem. Res. 1993;32;1645-1650. 43. Murat M, Amokrane A, Bastide JP, Montanaro L. Synthesis of zeolites from thermally activated kaolinite. Some observations on nucleation and growth. Clay Minerals 1992;27;119130.

44. Johnson EBG, Arshad SE. Hydrothermally synthesized zeolites based on kaolinite: A review. Appl. Clay Sci. 2014;97-98;215-221.

45. Doyle AM, Albayati TM, Abbas AS, Alismaeel ZT. Biodiesel production by esterification of oleic acid over zeolite Y prepared from kaolin. Renewable Energy 2016;97;19-23. 
46. Belviso C, Giannossa LC, Huertas FJ, Lettino A, Mangone A, Fiore S. Synthesis of zeolites at low temperatures in fly ash-kaolinite mixtures. Microporous Mesoporous Mater. $2015 ; 212 ; 35-47$.

47. Weiwei B, Lu L, Haifeng Z, Shucai G, Xuechun X, Guijuan J, Guimei G, Keyan Z. Removal of $\mathrm{Cu} 2+$ from aqueous solutions using Na-A zeolite from oil shale ash. Chinese $\mathrm{J}$. Chem. Eng. 2013;21(9);974-982.

48. Shawabkeh R, Al-Harahsheh A, Hami M, Khlaifat A. Conversion of oil shale ash into zeolite for cadmium and lead removal from wastewater. Fuel 2004;83;981-985.

49. Hu T, Qiu J, Wang Y, Wang C, Liu R, Meng C. Synthesis of low Si/Al ratio hydroxysodalite from oil shale ash without pretreatment. J. Chem. Technol. Biotechnol. $2015 ; 90 ; 208-212$.

50. Fernandes Machado NRC, Miotto DMM. Synthesis of Na-A and -X zeolites from oil shale ash. Fuel 2005;84;2289-2294.

51. Doyle AM, Alismaeel ZT, Albayati TM, Abbas AS. High purity FAU-type zeolite catalysts from shale rock for biodiesel production. Fuel 2017:199:394-402.

52. Narkhede N, Patel A. Efficient synthesis of biodiesel over a recyclable catalyst comprising a monolacunary silicotungstate and zeolite H-beta. RSC Adv. 2014;4;64379-64387.

53. Narkhede N, Patel A. Biodiesel production by esterification of oleic acid and transesterification of soybean oil using a new solid acid catalyst comprising 12-tungstosilicic acid and zeolite H-beta. Ind. Eng. Chem. Res. 2013;52;13637-13644.

54. Chung K-H, Chang D-R, Park B-G. Removal of free fatty acid in waste frying oil by esterification with methanol on zeolite catalysts. Bioresource Technol. 2008;99;7438-7443.

55. Vieira SS, Magriotis ZM, Ribeiro MF, Graça I, Fernandes, Lopes JMFM, Coelho SM, Santos NAV, Saczk AA. Use of HZSM-5 modified with citric acid as acid heterogeneous 
catalyst for biodiesel production via esterification of oleic acid. Microporous Mesoporous Mater. 2015;201;160-168.

56. Marchetti JM, Errazu AF. Comparison of different heterogeneous catalysts and different alcohols for the esterification reaction of oleic acid. Fuel 2008;87;3477-3480.

57. Sun K, Ma L, Han Y, Fu Z, Ding J. A comparative study on the catalytic performance of different types of zeolites for biodiesel production. Fuel 2015:158:848-854.

58. Figueiredo KCS, Salim VMM, Borges CP. Ethyl oleate production by means of pervaporation-assisted esterification using heterogeneous catalysis. Brazilian J. Chem. Eng. 2010:27:609-617.

59. Han Y, Lv E, Ma L, Lu J, Chen K, Ding J. Coupling membrane pervaporation with a fixedbed reactor for enhanced esterification of oleic acid with ethanol. Energy Conv. Management. 2015:106:1379-1386.

60. Rothenberg G. Catalysis: concepts and green applications. John Wiley \& Sons: 2015.

61. Levenspiel O. Chemical reaction engineering. 3rd ed. New York: John Wiley and Sons; 1999.

62. Carberry J. Chemical and catalytic reaction engineering. New York: McGraw-Hill; 1976.

63. Poling BE, Prausnitz JM, O’Connell JP. The properties of gases and liquids. 5th ed. New York: McGraw-Hill; 2004.

64. Veljković VB, Stamenković OS, Todorović ZB, Lazić ML, Skala DU. Kinetics of sunflower oil methanolysis catalyzed by calcium oxide. Fuel 2009;88:1554-62. 


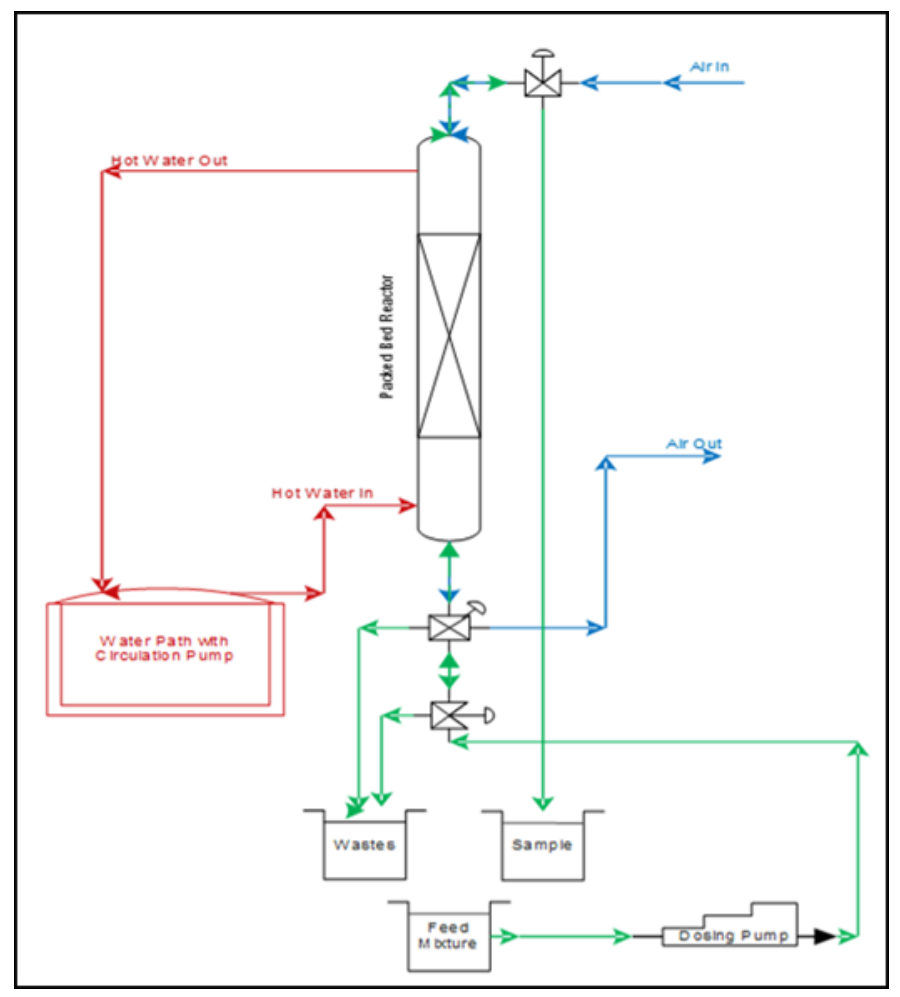

Fig. 1: Schematic of continuous fixed-bed reactor. 

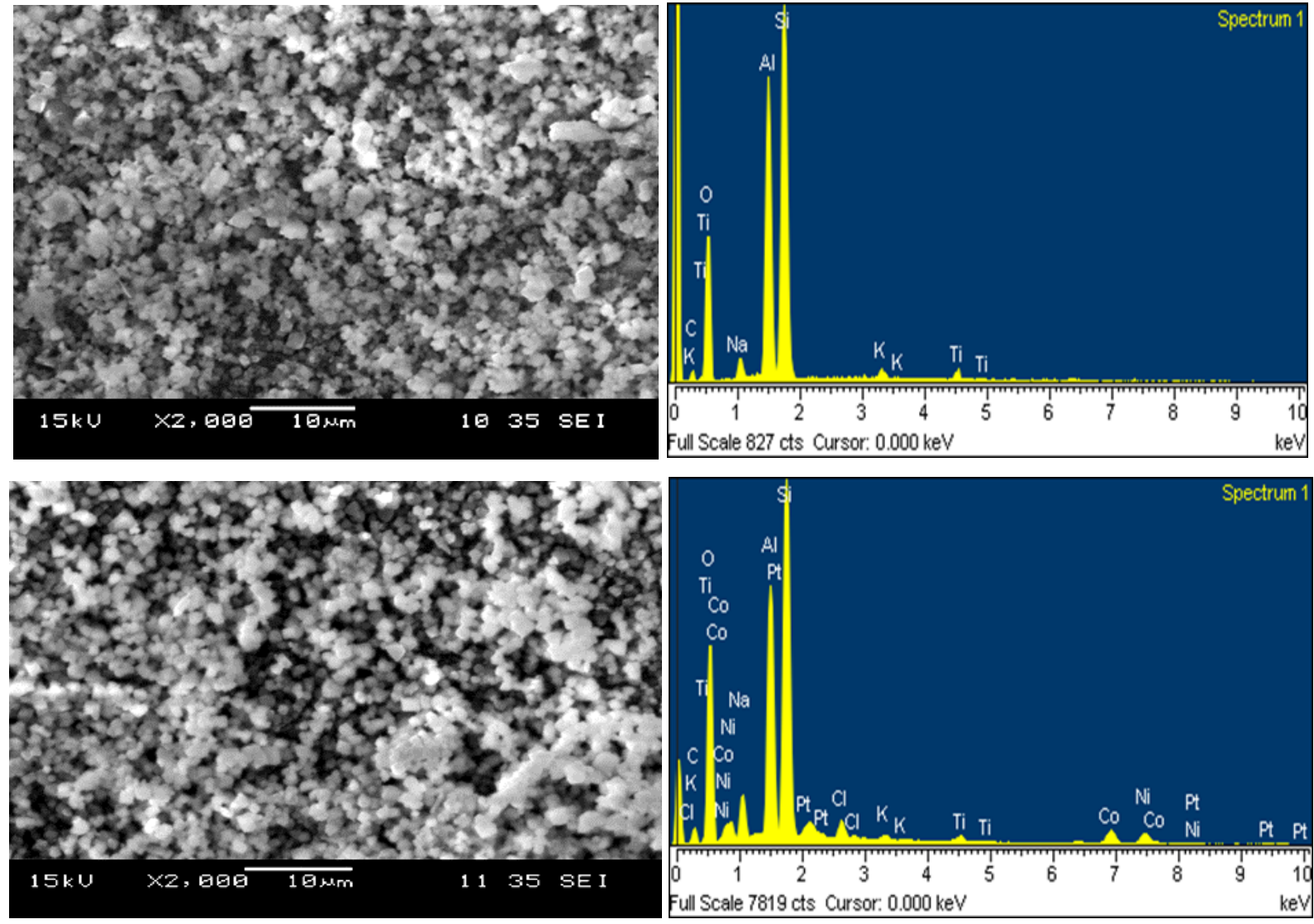

Fig. 2: SEM and EDAX images for H-FAU (top) and Co-Ni-Pt-FAU (bottom). 

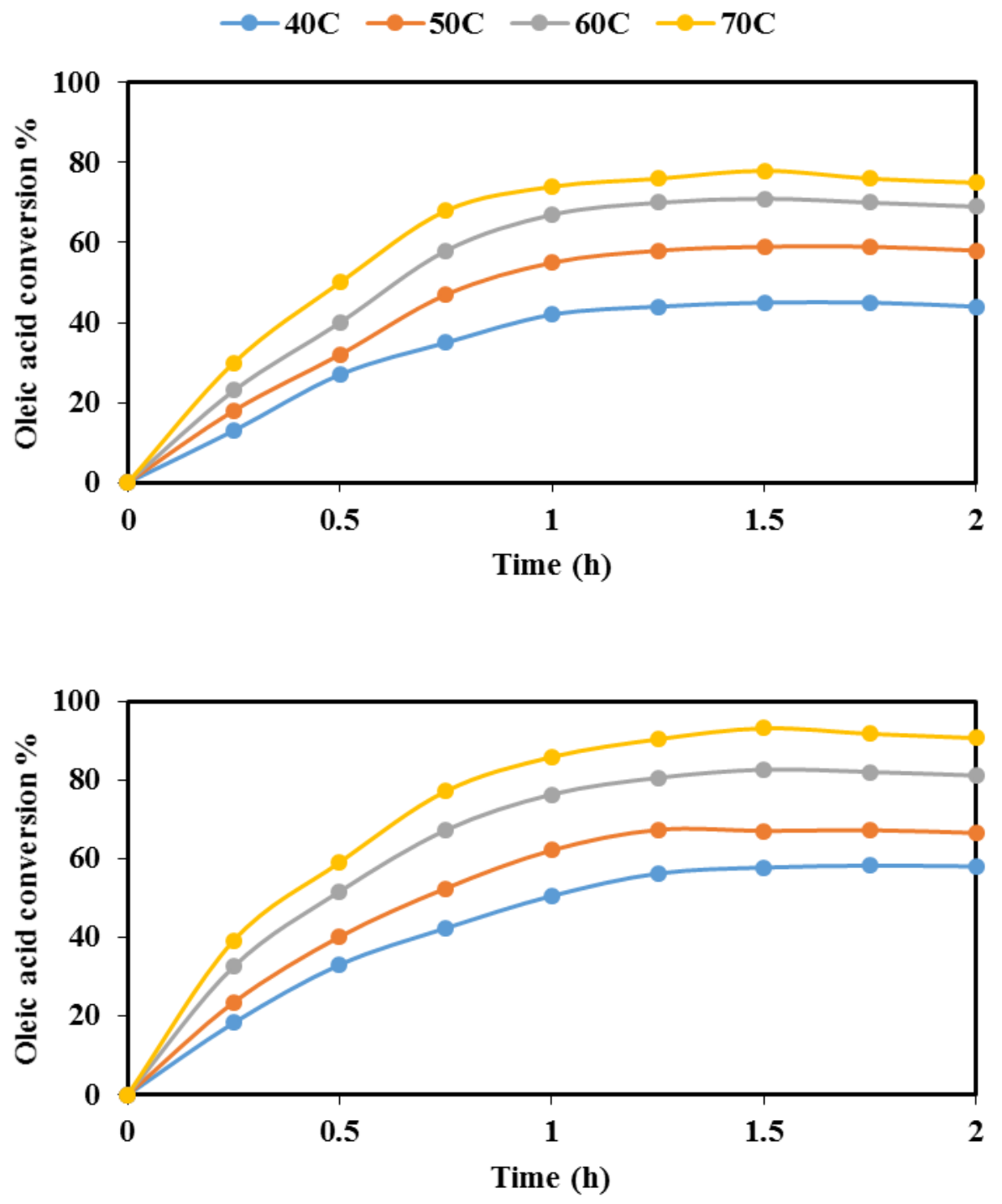

Fig. 3: Oleic acid conversion vs. reaction temperature in batch reactor: H-FAU (top) and CoNi-Pt-FAU (bottom). 

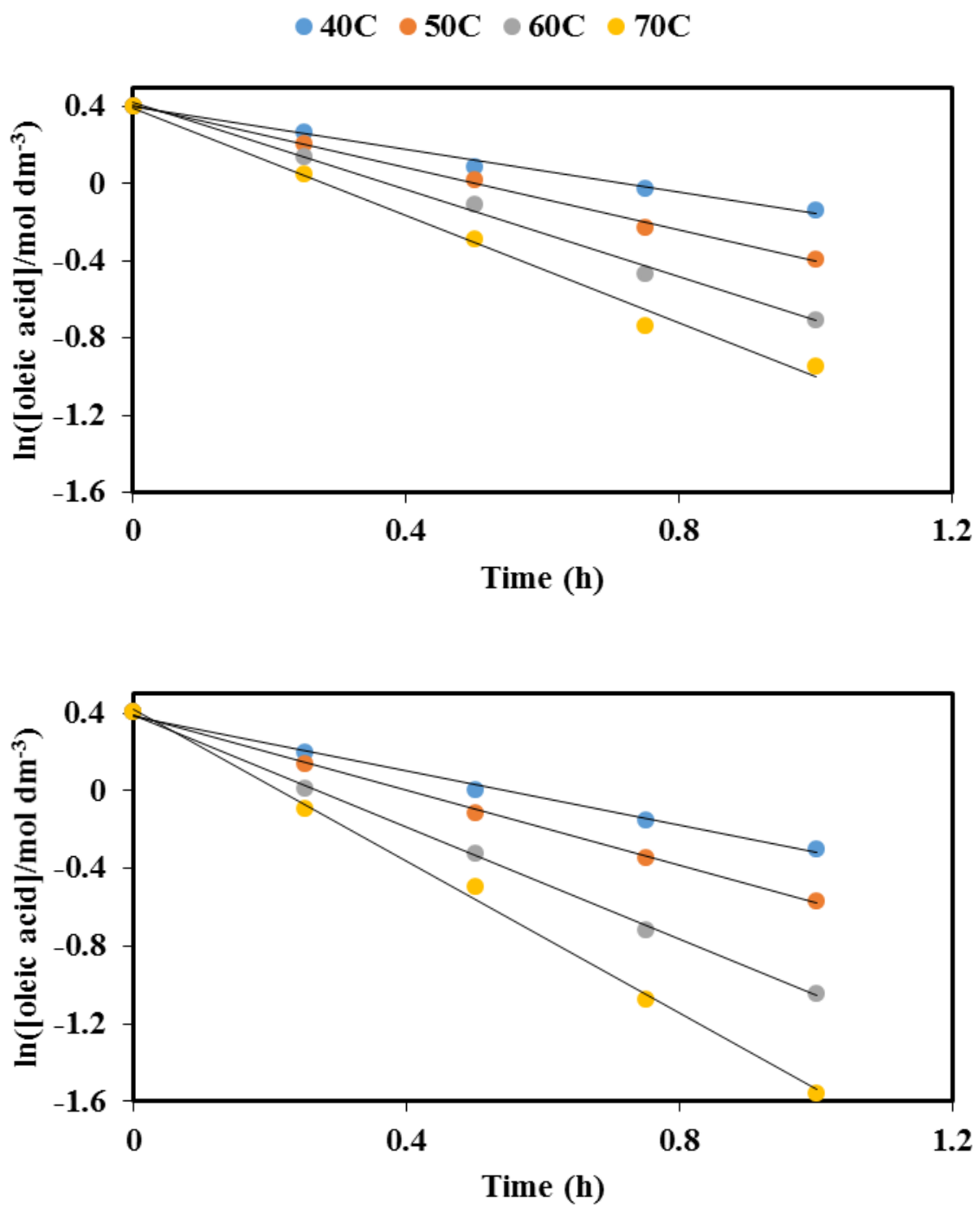

Fig. 4: Pseudo first-order plots vs. reaction temperature in batch reactor, FAU (top) and Co-NiPt-FAU (bottom). 


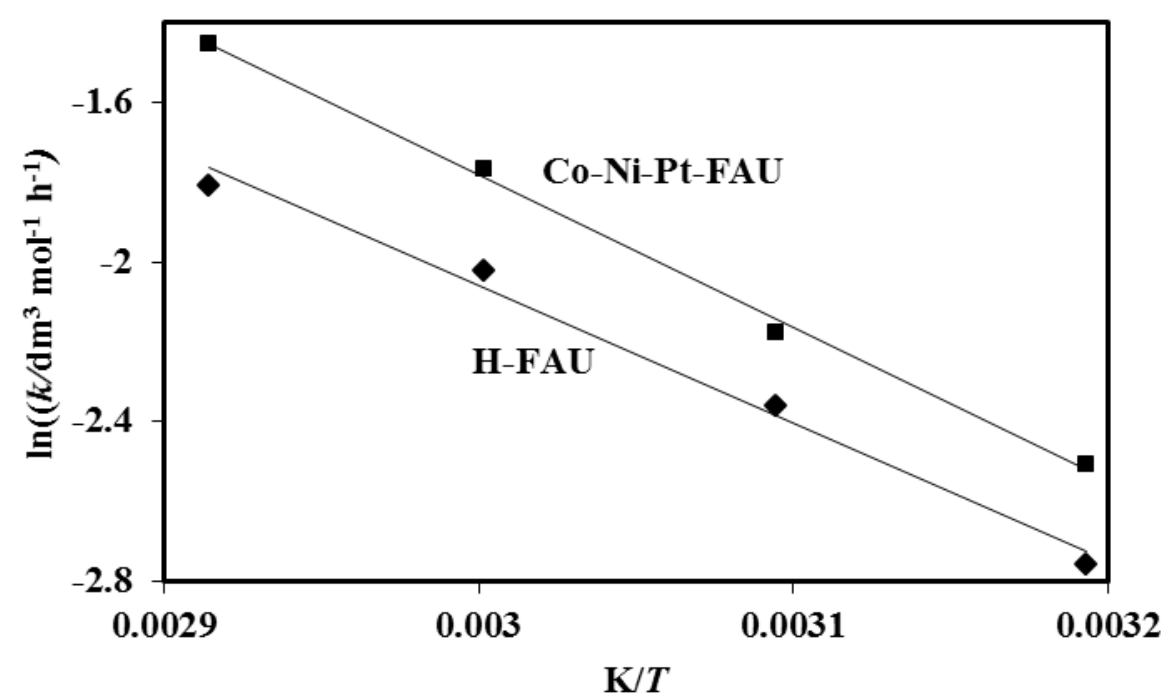

Fig. 5: Arrhenius plots for oleic acid esterification in batch reactor. 

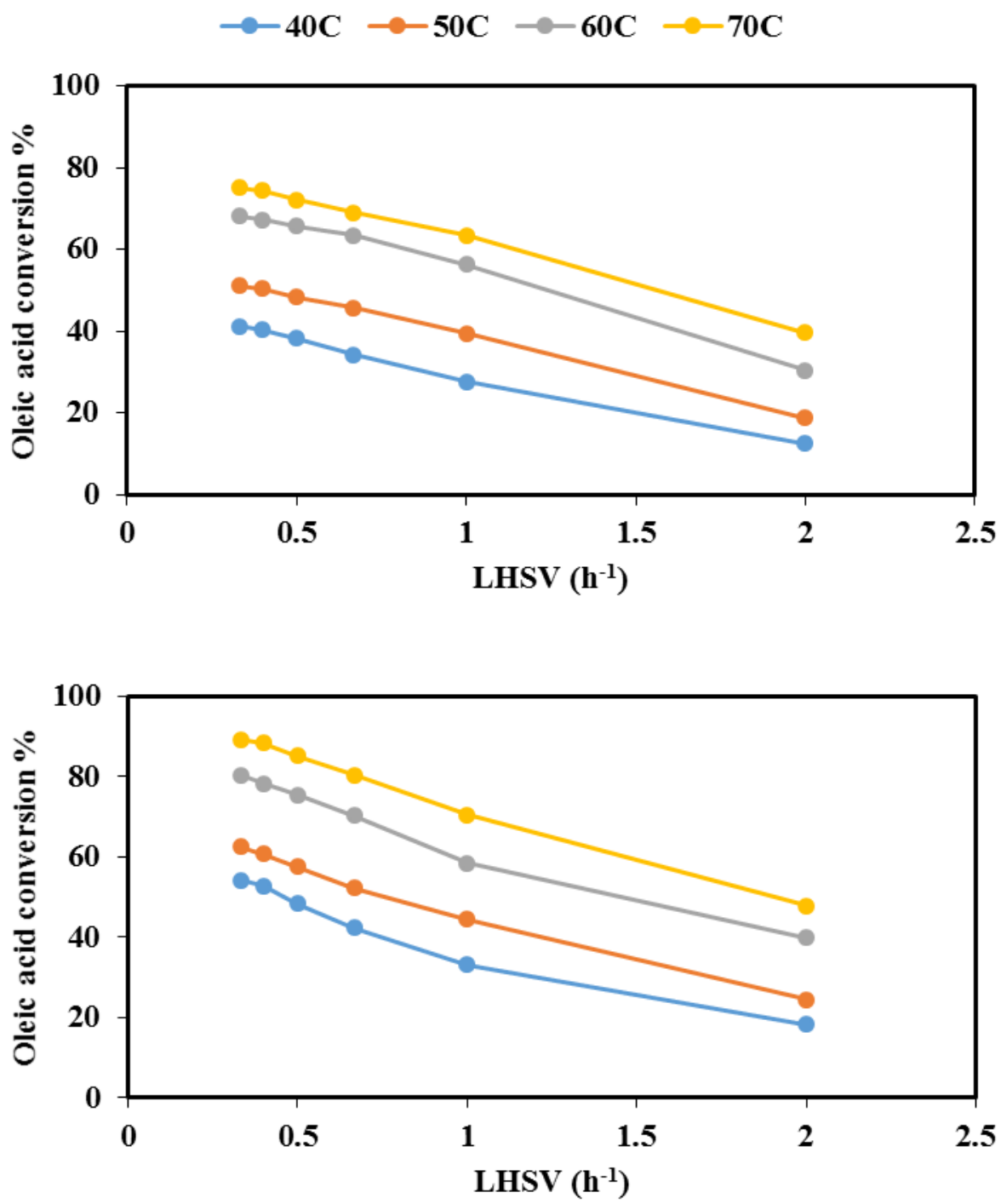

Fig. 6: Oleic acid conversion vs. LHSV and reaction temperature in continuous fixed-bed reactor: H-FAU (top) and Co-Ni-Pt-FAU (bottom). 

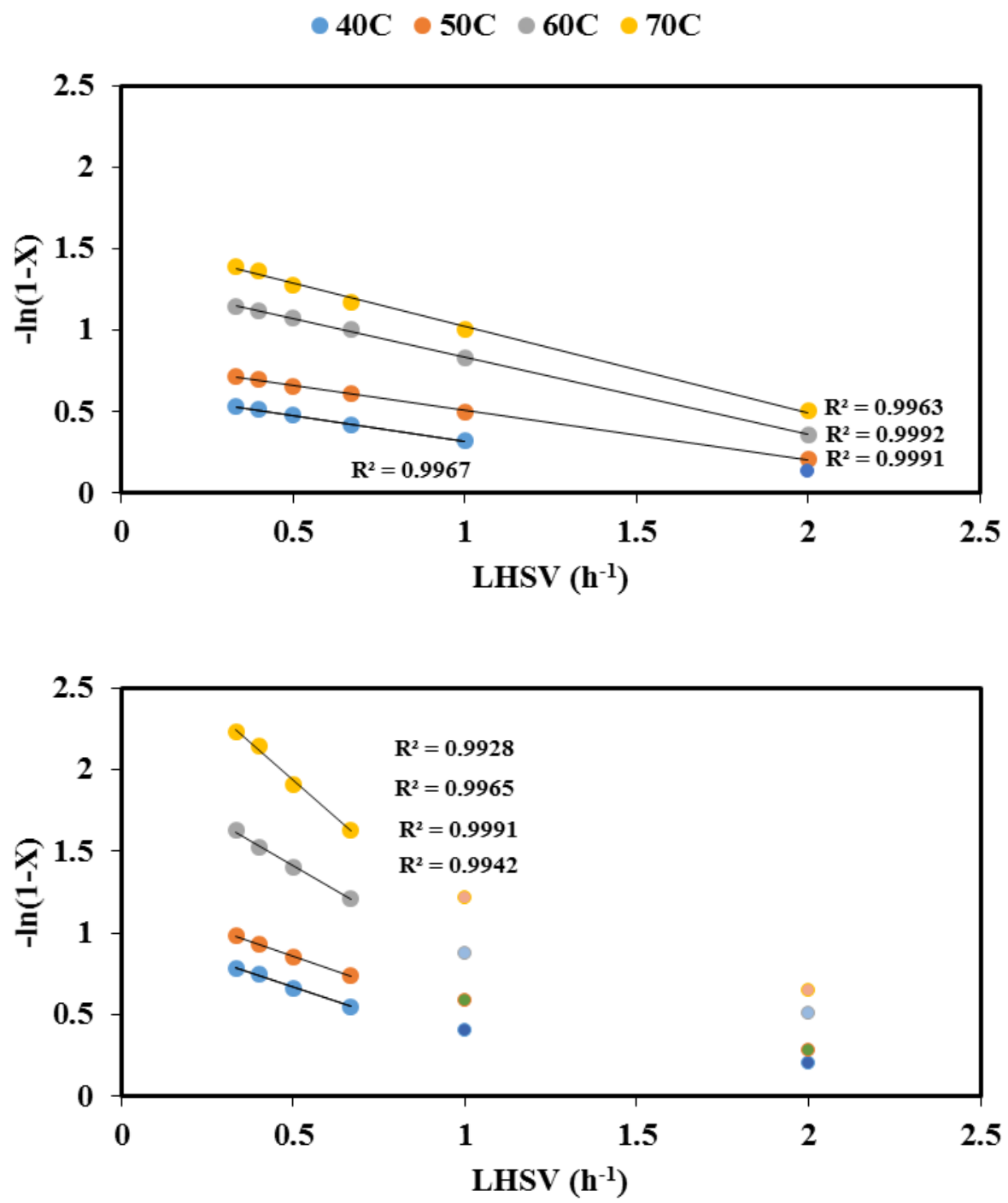

Fig. 7: Psuedo first-order plots vs. LHSV and reaction temperature in continuous fixed-bed reactor: H-FAU (top) and Co-Ni-Pt-FAU (bottom). 

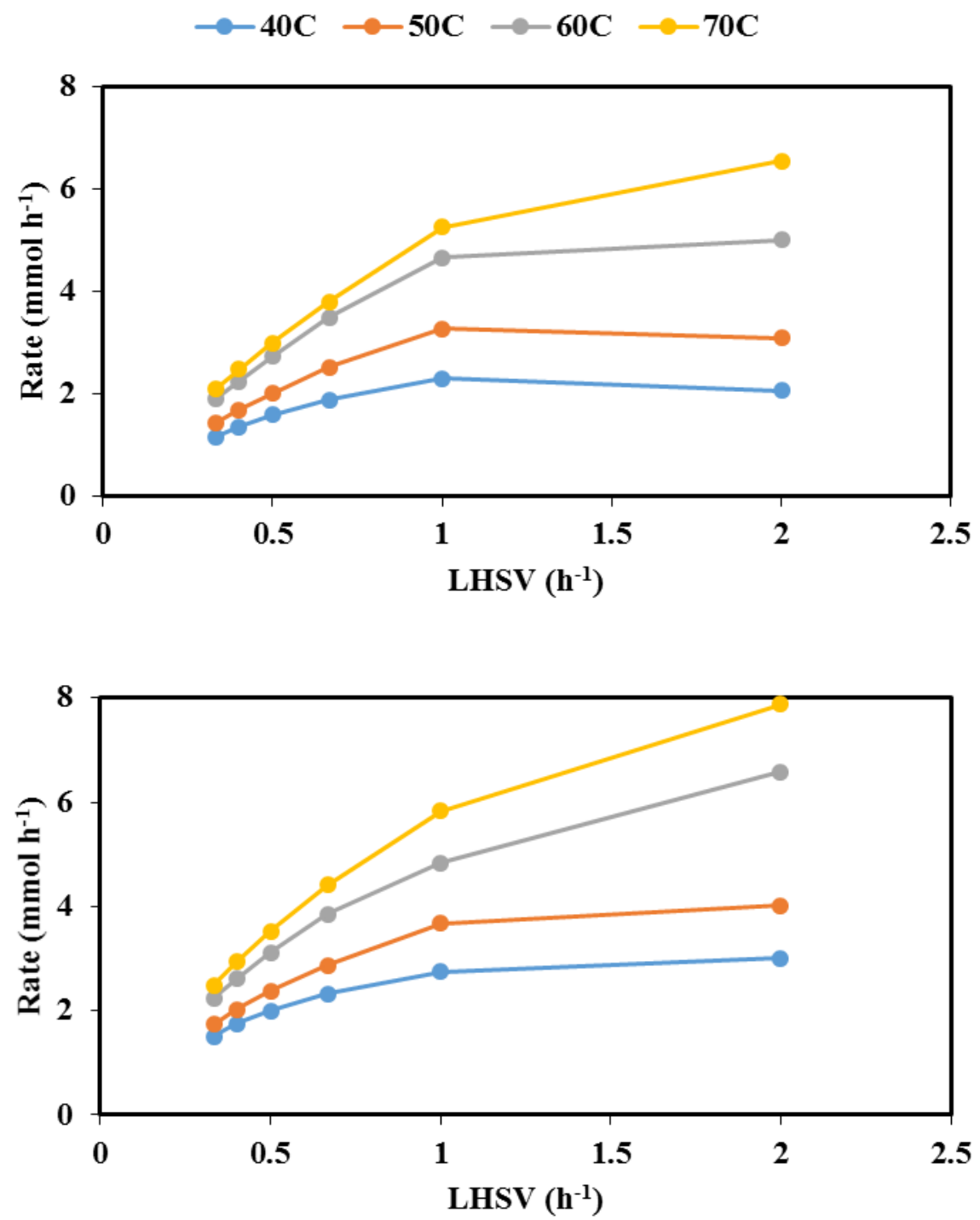

Fig. 8: Reaction rate (of oleic acid) vs. LHSV and reaction temperature in continuous fixedbed reactor: H-FAU (top) and Co-Ni-Pt-FAU (bottom). 
Table 1: Pseudo first-order rate constants, second order rate constants, Thiele modulus and thermodynamic data for oleic acid esterification using H-FAU and Co-Ni-Pt-FAU in batch conditions.

\begin{tabular}{|c|c|c|c|c|c|c|}
\hline \multirow[b]{2}{*}{$\mathrm{T} /{ }^{\circ} \mathrm{C}$} & \multicolumn{3}{|c|}{ H-FAU } & \multicolumn{3}{|c|}{ Co-Ni-Pt-FAU } \\
\hline & $k^{\prime} / h^{-1}$ & $k / \mathrm{dm}^{3} \mathrm{~mol}^{-1} \mathrm{~h}^{-1}$ & $\phi / 10^{-4}$ & $k^{\prime} / h^{-1}$ & $k / \mathrm{dm}^{3} \mathrm{~mol}^{-1} \mathrm{~h}^{-1}$ & $\phi / 10^{-4}$ \\
\hline 40 & 0.552 & 0.0635 & 5.68 & 0.704 & 0.0816 & 6.42 \\
\hline 50 & 0.813 & 0.095 & 6.23 & 0.969 & 0.113 & 6.81 \\
\hline 60 & 1.13 & 0.133 & 6.68 & 1.44 & 0.171 & 7.54 \\
\hline 70 & 1.39 & 0.164 & 6.74 & 1.96 & 0.234 & 8.01 \\
\hline$E a / \mathrm{kJ} \mathrm{mol}^{-1}$ & \multicolumn{3}{|c|}{28.6} & \multicolumn{3}{|c|}{31.9} \\
\hline $4 / \mathrm{dm}^{3} \mathrm{~mol}^{-1} \mathrm{~h}^{-1}$ & \multicolumn{3}{|c|}{3886} & \multicolumn{3}{|c|}{16804} \\
\hline
\end{tabular}

